\title{
Leitura literária no ensino médio
}

Lovani Volmer ${ }^{1}$

Ana Cândida Carvalho ${ }^{2}$

Luciano Santos ${ }^{3}$

\section{Resumo}

Este estudo discute a importância da narrativa literária na constituição do sujeito e analisa, em uma perspectiva discursiva, textos multissemióticos produzidos a partir da leitura de contos de Machado de Assis, a fim de averiguar a posição axiológica dos adolescentes, seu olhar sobre si e o outro, seus hábitos culturais, seus posicionamentos ideológico-políticos, seus traços identitários, seus sonhos e utopias. Esse projeto de leitura, realizado com alunos de Ensino Médio, remete a uma perspectiva possível de escolarização da literatura, capaz de promover autoconhecimento, participação ativa, crítica e criativa de jovens, favorecendo a diversidade, a aprendizagem significativa e colocando o professor como mediador do processo.

Palavras-chave: Discurso; Leitura na Escola; Mediação; Multiletramentos; Narrativas Literárias.

\section{Literary reading in high school}

\section{Abstract}

This study discusses the importance of literary narrative in the constitution of the subject and analyzes, in a discursive perspective, multisemiotics texts produced from the reading of stories by Machado de Assis and to find out the axiological position of the teenagers, their look about themselves and the others, their cultural habits, their ideological-political positions, their identity traits, their dreams and utopias. This reading project, carried out with high school students, as a possible perspective of literature schooling, capable of promoting self-knowledge, engaging, critical and creative participation of young people, favoring diversity, meaningful learning and placing the teacher as a mediator of process.

Keywords: Speech; Reading at School; Mediation; Multiletraments; Literary Narratives.

\section{Introdução}

A narrativa acompanha a história da humanidade, está presente em todas as sociedades, em todos os tempos e lugares; tudo o que se conta é narrativo. Estamos imersos em estruturas narrativas, em que, destacamos, encontramos as formas linguísticas e discursivas com as quais construímos e expressamos nossa subjetividade. Desse jogo linguístico, sempre participam também os ouvintes/leitores - a construção de uma narrativa

\footnotetext{
${ }^{1}$ Universidade Feevale, Novo Hamburgo/RS, lovaniv@feevale.br

2 Universidade Feevale, Novo Hamburgo/RS, anacsc@feevale.br

${ }^{3}$ Universidade Feevale, Novo Hamburgo/RS, lucianosantos2@feevale.br
} 
precisa de sua cooperação - e, como não há narrativa sem narrador e sem ouvinte/leitor, a narrativa verbal é construída dialogicamente, em um discurso. A habilidade de narrar, sendo específica do ser humano e sua inteligência, é, pois, parte integrante da sua competência linguística e simbólica.

Assim, a história de nossa vida depende, em grande parte, do conjunto de histórias que já lemos, vimos ou ouvimos, uma vez que é a partir delas que aprendemos a construir a nossa. Quando lemos uma história, por exemplo, não só transformamos o texto, mas nos transformamos também. Nesse sentido, este estudo discute um projeto de leitura, realizado com alunos de Ensino Médio em uma escola comunitária gaúcha, como possibilidade de escolarização da literatura, capaz de promover autoconhecimento, participação ativa, crítica e criativa de jovens, favorecendo a diversidade, a aprendizagem significativa e colocando o professor como mediador, divulgador e revitalizador da literatura.

Em uma perspectiva discursiva, com base nos estudos de Bakhtin (2006, 2010, 2011), e considerando o gênero discursivo como orientador das práticas de linguagem, analisa-se um roteiro cinematográfico e um curta-metragem, produzidos a partir da leitura de contos de Machado de Assis. Dessa análise, pretende-se averiguar a posição axiológica dos adolescentes, seu olhar sobre si e o outro, seus hábitos culturais, seus posicionamentos ideológico-políticos, seus traços identitários, seus sonhos e utopias.

\section{A leitura de narrativas literárias e a constituição do sujeito}

A leitura - nesses tempos em que somos bombardeados por informações e o pensamento faz-se raro - apresenta-se como alternativa que ajuda o leitor a se construir, a imaginar outras possibilidades, a sonhar, a expandir seus horizontes. Para que isso se efetive, porém, não basta identificar o significante isoladamente, é preciso compreender o significado do texto como um todo; o que se compreende, por exemplo, não são as palavras em sua disposição gráfica, mas o pensamento em movimento em campos semânticos por meio do jogo de várias sintaxes.

Ser leitor, por sua vez, vai além de possuir um hábito ou atividade regular, é operar um trabalho produtivo, reescrever, alterar sentido, é ser transformado, é o próprio meio pelo qual 
nos organizamos. Ao ler um texto e compreendê-lo, o leitor não só o transforma, mas também se transforma, o que faz desta uma atividade fundamental à formação do indivíduo. A leitura teria, portanto, função libertadora, uma vez que o leitor vai além das palavras, ao não deixar que elas

se solidifiquem e nos solidifiquem, [ler] é manter aberto o espaço líquido da metamorfose. A fidelidade às palavras é reaprender continuamente a ler e a escrever (a escutar e a falar). Somente assim pode-se escapar, mesmo que provisoriamente, da captura social da subjetividade, a essa captura que funciona obrigando-nos a ler e a escrever de um modo fixo, com um padrão regular. Somente assim pode-se escapar, mesmo que seja por um momento, dos textos que nos modelam, do perigo das palavras que, ainda que verdadeiras, se convertem em falsas uma vez que nos contentamos com elas. [...] Somente assim a educação manterá seu sentido original, que deriva de exducere, sua etimologia latina: conduzir para fora, fora do que é único, fora do caminho traçado de antemão, fora do já dito, do já pensado, do já interpretado (LARROSA, 2003, p.628 - tradução nossa).

Para que a obra alcance sua realidade estética, ou seja, a sua concretização, é preciso, pois, que seja lida, transformada para transformar, ganhe vida para dar vida. É preciso interação com o receptor, que, a cada leitura, baseando-se em seus conhecimentos, extrai novos significados desse texto e, ao compreendê-lo, cria, modifica, elabora e incorpora novos conhecimentos em seus esquemas mentais. Assim, mesmo sendo materialmente a mesma, a obra transforma-se a cada leitura, uma vez que o leitor e a situação de leitura não são os mesmos de outrora. O leitor é, nesse sentido, peça-chave quando o assunto é leitura; é ele que atribui "vida" e, portanto, sentido ao escrito.

Reconhecendo que aquilo que é indispensável para nós também o é para o outro, parafraseamos Candido (1995), quando se manifesta acerca dos Direitos Humanos e da Literatura, e consideramos a leitura igualmente um direito. O autor considera que são direitos do ser humano não apenas aqueles bens que asseguram sobrevivência física em níveis decentes, tais como moradia, alimentação, vestuário, instrução, saúde, entre outros, mas também os que garantem a integridade espiritual, como o direito à crença, à opinião, à arte e à literatura 4 .

\footnotetext{
${ }^{4}$ Candido $(1995$, p.242) considera literatura "todas as criações de toque poético, ficcional ou dramático em todos os níveis de uma sociedade, em todos os tipos de cultura, desde o que chamamos folclore, lenda, chiste, até as formas mais complexas e difíceis da produção escrita das grandes civilizações."
}

Periódico Horizontes - USF - Itatiba, SP - Brasil - e020023 
A leitura literária possibilita ao leitor compreender a diversidade de conteúdos que o conformam como ser humano, sociável e histórico. Ao aproximá-lo da linguagem artística, ela possibilita-Ihe apropriar-se de sua riqueza, de sua beleza, da amplitude de seus horizontes, de diferentes percepções de mundo, de universos culturais distintos;

é o sonho acordado das civilizações. [...], ela é fator indispensável de humanização e, sendo assim, confirma o homem na sua humanidade, inclusive porque atua em grande parte no subconsciente e no inconsciente. [...] Cada sociedade cria as suas manifestações ficcionais, poéticas e dramáticas de acordo com os seus impulsos, as suas crenças, os seus sentimentos, as suas normas [...]. Ela não corrompe nem edifica, portanto; mas, trazendo livremente em si o que chamamos o bem e o que chamamos o mal, humaniza em sentido profundo, porque faz viver (CANDIDO, 1995, p.243-244).

O texto literário pode, nesse sentido, ser uma forma de conhecimento, pois permite ao leitor, sem sair do aconchego de seu lar - ou da sala de aula, seja no campo ou na cidade, no centro ou na periferia, viajar, simplesmente viajar, para lugares próximos ou distantes. Conforme sua imaginação permitir, ele pode ir ao passado, ao presente, ao futuro ou, ainda, a outras eras e, mais do que isso, "viver" nesse espaço e nesse tempo e, ao final, ao término da viagem, com certo ar de nostalgia, ficar com "gostinho de quero mais", querendo embarcar na próxima viagem literária, porque nela encontramos o calor que nos aquece e com que, muitas vezes, não nos deparamos em nosso próprio destino.

Ao abordar a leitura literária em seus estudos, Barthes (1989) destaca a profunda relação entre língua e poder e vê na literatura a possibilidade de "trapacear" com a língua. Para o autor, as "forças de liberdade que residem na literatura não dependem da pessoa civil, do engajamento político do escritor que, afinal, é apenas um 'senhor' entre outros, nem mesmo do conteúdo doutrinal de sua obra, mas do trabalho de deslocamento que ele exerce sobre a língua" (BARTHES, 1989, p.17).

A literatura não é, pois, uma experiência separada da vida. A ficção permite que digamos o que talvez não saibamos expressar e, ao mesmo tempo, nos fala de maneira mais precisa o que queremos dizer ao mundo e, muitas vezes, a nós mesmos. Além disso, a experiência literária não só nos permite saber da vida pela experiência do outro, mas também vivenciar essa experiência, incorporando a nós aquilo que não somos, mas que temos a 
possibilidade de ser.

De acordo com Iser (1999, p.6), "não há nenhum objeto concreto que corresponda a eles [textos literários] no mundo real, apesar de certamente constituírem seus objetos a partir de elementos encontrados nesse mundo real". O texto literário não pode, pois, ser plenamente identificado nem com objetos reais do mundo exterior nem com as experiências do leitor, o que, segundo o autor, produz certo grau de indeterminação.

Em outro estudo, Iser (1996) considera que a arte literária tem um substrato de alta plasticidade, que desconhece qualquer tipo de constantes e manifesta-se na reformulação do já formulado como um meio que atualiza, nas formas da escrita, o que, independentemente dele, permanece inacessível. $\mathrm{O}$ estudioso ressalta que se o texto ficcional se refere à realidade sem se esgotar nessa referência, então a repetição é um ato de fingir, por meio do qual aparecem finalidades que não pertencem à realidade repetida. Assim, o que retorna ao texto ficcional é uma realidade de todo reconhecível, posta, entretanto, sob o signo do fingimento 5 .

Pelo reconhecimento do fingir, todo o mundo organizado no texto literário transforma-se em um como se, o que significa que o mundo representado não é propriamente mundo, mas que, por efeito de um determinado fim, deve ser representado como se fosse. Para Iser (1999, p.8):

Em primeiro lugar, [o texto literário] difere de outras formas de escrita, porque não escreve sobre objetos reais nem os constitui. Em segundo lugar, diverge das experiências reais do leitor, na medida em que oferece enfoques e abre perspectivas nas quais o mundo empiricamente conhecido de nossa experiência pessoal aparece mudado.

Como se pode ser denominado de imaginário, porque os atos de fingir se relacionam com o imaginário. Para o estudioso alemão, o sentido do texto não é dado explicitamente, isto é, atualiza-se apenas na consciência imaginativa do leitor. Além disso, o mundo relacionado no texto não se refere a si mesmo e, por seu caráter remissivo, representa algo diverso de si próprio. Os signos icônicos de textos ficcionais têm, pois, a função de produzir significados, não simplesmente designar significados a determinados significantes. $\mathrm{O}$ texto atualiza-se apenas no

${ }^{5}$ Corroboramos Searle (2002) quando se manifesta acerca da ficção. Segundo o estudioso, ela não pode ser classificada como fraudulenta, enganosa ou mentirosa, ou seja, "fingir fazer ou ser alguma coisa é envolver-se numa representação, é agir como se estivesse fazendo ou fosse essa coisa, sem nenhuma intenção de enganar". (p.105).

Periódico Horizontes - USF - Itatiba, SP - Brasil - e020023 
sujeito, a quem cabe imaginar o que os signos, no contexto em que estão inseridos, passaram a excluir.

O mundo concebido é apenas um mundo possível, de um lado, diferenciando-se daqueles mundos de cujo material foi feito e, de outro, oferece uma marcação para uma realidade a ser imaginada, o que, para Iser (1999), pode ser o motivo pelo qual os textos literários são resistentes ao tempo: "não porque representam valores eternos supostamente independentes do tempo, mas porque sua estrutura permite ao leitor continuamente colocarse dentro do mundo ficcional" (ISER, 1999, p.41). A leitura desenvolve o texto como processo de realização, por isso o constitui como realidade.

Durante a leitura, o leitor faz projeções, ou seja, "a relação entre texto e leitor se estabiliza através do feedback constante no processo da leitura pelo qual se ajustam as imprevisibilidades do texto" (ISER, 1999, p.125). O texto ficcional deve, pois, ser visto como comunicação, que se realiza pela autocorreção latente dos significados construídos pelo leitor, enquanto sua leitura se apresenta como uma relação dialógica.

O dialogismo é uma ciência das relações, concebida por Bakhtin (2011) ao se aproximar da relatividade de Einstein e descobrir a existência de um diálogo contínuo entre os fenômenos do mundo, em que nada escapa ao mecanismo das relações. O conceito de dialogismo se sustenta na noção de vozes que se enfrentam em um mesmo enunciado e que representam não só a voz das personagens, mas dos diferentes elementos históricos, sociais e linguísticos que atravessam a enunciação. Para Bakhtin (2011), o aspecto ideológico é inerente à linguagem humana, ou seja, tudo o que é dito/escrito não pode ser concebido como original, uma vez que nesse discurso se cruza o já dito no/do diálogo social.

O sujeito se constitui, nesse sentido, na relação com o outro, ou seja, a identidade é dada pela alteridade. No processo dialógico, os sujeitos do diálogo se alteram em processo (devir), isto é, o enunciado afirmado por alguém passa a fazer parte de todos os enunciados, numa cadeia infinita. Em Bakhtin, o sujeito é um epifenômeno, uma vez que é atravessado pelo sujeito coletivo. Para o estudioso, ainda, só o outro pode nos dar acabamento, assim como só nós podemos dar acabamento a um outro. Eis o princípio dialógico bakhtiniano, a exotopia, importante conceito no estudo do dialogismo.

Assim, a narrativa literária consiste em um ato de fala cuja intenção é iniciar e orientar 
uma busca por significados entre um espectro de significados possíveis. Nessa busca de possibilidades e por uma experiência criadora de mundos, de conhecimento e, portanto, libertadora na escola, propomos, a partir da leitura e análise de textos literários, mais especificamente de contos de Machado de Assis, a recriação das histórias e sua transformação em curta-metragem.

\section{Projeto Outros Olhares: a voz e o protagonismo juvenil}

O "Projeto Outros Olhares", objeto de análise deste estudo, consiste na adaptação de contos de Machado de Assis em curtas-metragens e é desenvolvido, anualmente, desde 2002 até o momento, com alunos da segunda etapa do primeiro ciclo do Ensino Médio ${ }^{6}$, em uma escola comunitária da região metropolitana de Porto Alegre, desde o ano de 2002. Uma das premissas da escola é a quebra de alguns paradigmas, por meio de avaliação processual, organização por ciclos de aprendizagens, aulas inter-, trans- e multidisciplinares, além do desensalamento, com propostas de trabalhos por projetos, workshops, entre outras práticas. Desde que foi criado, o Projeto vem se transformando, sempre no sentido de acompanhar, cada vez mais, a proposta de uma escola conectada às demandas do século XXI.

Quando da sua criação, cientes de que o ensino nas aulas de Literatura e Língua Portuguesa não podiam se restringir à transmissão de regras gramaticais ou ao estudo de características das épocas literárias, buscavam-se alternativas de trabalho para essas aulas. Partiu-se da certeza de que a leitura literária extrapola a recepção passiva, para configurar-se em uma atividade participativa do leitor, já que a literatura dá espaço à pluralidade de vozes, o que contribui para a formação de sujeitos autônomos, críticos e criadores.

Em todos esses anos, aproximadamente 1800 estudantes já tiveram participação direta no Projeto, ou seja, são quase dois mil adolescentes que tiveram a possibilidade de ler textos literários não para produzir (ou copiar) resumos, fichas de leitura ou questionários, mas para submergir no universo da narrativa literária e compreendê-la como produção humana, repleta de experiências, capaz de provocar crítica sobre si mesmo, deixar marcas nas culturas pelas quais atravessa e permitir "entender quem somos e aonde chegamos" (CALVINO, 1993, p.16).

\footnotetext{
${ }^{6} \mathrm{~A}$ escola é ciclada e a etapa em questão corresponde ao $2^{\circ}$ ano do Ensino Médio.
} 
Muitas já foram as obras literárias que nortearam o trabalho, porém, neste estudo, ater-nos-emos às leituras e releituras realizadas de contos de Machado de Assis, cuja proposição pretendia, além de aproximar os jovens leitores de textos literários e instigá-los à leitura, possibilitar o contato com a obra daquele que é um dos maiores escritores da literatura brasileira e que também pudesse ressoar nos jovens leitores da atualidade. Independentemente da época, do mundo representado, seus contos têm algo a dizer a leitores contemporâneos e, referente ao foco deste estudo, a leitores jovens em idade escolar, que, no século XXI, têm a possibilidade de, pela literatura, ter contato com posições axiológicas de outra época, de estabelecer relações com a atualidade, de refletir sobre a língua e suas variantes, como forma de expressão e identidade dos grupos sociais e da época em foco.

Paralelo às leituras, estudaram-se a contextualização histórica e alguns elementos característicos da obra de Machado, mais precisamente de seus contos. O mundo fictício machadiano não se apresenta dentro de uma ordem e linearidade rígidos, com causa e efeito necessariamente estabelecidos e determinados; há lugar para desordens, acidentes e contradições. Em seus contos, o imprevisível, o inexplicável, os desencontros configuram as relações interpessoais. Assim sendo, procurou-se investigar o realismo enigmático do autor, com tramas e desfechos que põem à mostra as vaidades humanas, as máscaras do cotidiano, desnudando as aparências.

Depois das leituras e reflexões, que, na atualidade, não se restringem às aulas de Literatura e Língua Portuguesa, mas dão norte a um projeto de estudos interdisciplinar, os alunos foram desafiados, a partir das leituras que fizeram, a escolher uma das obras de Machado e transformarem-na em roteiro de curta-metragem, adaptando a história, trazendo um novo olhar que cruzasse pela narrativa sem que ela se perdesse, permitindo-se pensar, refletir e questionar o mundo multicultural, complexo e confuso em que vivem. Nesse exercício de escolhas, percebemos que os alunos demonstraram preferência pelos contos, entre eles "A cartomante”, “O alienista”, "Pai contra mãe”, "Conto de escola”, "O espelho”, porque, segundo eles, continuam atuais e tratam de questões que dizem respeito à essência humana: relações de poder, livre arbítrio, condicionamento social, relações interpessoais e introspectivas, falta de empatia. Essas percepções, discutidas com e entre os alunos após as leituras, retratam, pelo discurso e a partir do como se de Iser (1979), o olhar dos adolescentes sobre si e o outro, as 
suas percepções acerca da sociedade de que fazem parte, promovendo uma prática de ensinoaprendizagem voltada não para a conformação a ideias pré-estabelecidas, mas para o posicionamento crítico, a cidadania.

Visando à instrumentalização dos alunos no que diz respeito às especificidades de um roteiro de curta-metragem, assistiu-se a trechos do filme "Cidade de Deus", fazendo-se comparações entre a história roteirizada e a assistida, assim como a análise da linguagem específica de cada gênero, as escolhas lexicais, os ângulos e enquadramentos na filmagem. Concluída essa etapa, os alunos criaram, com base em seu repertório de leituras, os seus próprios roteiros.

Trata-se, pois, de autoria, o que remete aos estudos de Bakhtin (2011). Para falar sobre a posição do autor na prosa romanesca, segundo o estudioso, é preciso, inicialmente, distinguir o autor-pessoa, o escritor, do autor-criador, que é um constituinte do objeto estético, responsável pela sua forma, aquele que não apenas registra passivamente os eventos da vida, mas os recorta e os reorganiza, a partir de uma posição axiológica.

O autor-criador é, para Bakhtin, componente da obra; ele não é simplesmente o escritor, nem o narrador ou uma instância gramatical do texto, mas a consciência de uma consciência, que engloba e dá acabamento à consciência do herói e do seu mundo:

A consciência do autor é a consciência da consciência, isto é, a consciência que abrange a consciência e o mundo da personagem, que abrange e conclui essa consciência da personagem com elementos por princípio transgredientes a ela mesma e que, sendo imanentes, a tornariam falsa (BAKHTIN, 2011, p.11).

De acordo com Bakhtin (2011), mesmo que a voz do autor-criador seja a do escritor como pessoa, ela só será esteticamente criativa se o escritor for capaz de trabalhar em sua linguagem permanecendo fora dela, ou seja, é preciso um excedente de visão e conhecimento, ao que Bakhtin chama de princípio da exterioridade. É esse excedente de visão, no tempo e no espaço, que dá sentido estético à consciência do outro, que lhe dá forma e acabamento. Para Bakhtin (2011, p.176-7):

Encontrar o enfoque essencial à vida de fora dela - eis o objetivo do artista. Com isso o artista e a arte criam, em linhas gerais, uma visão absolutamente 
nova do mundo, uma imagem do mundo, a realidade da carne mortal do mundo que não é conhecida de nenhum dos outros ativismos criativoculturais. [...] $\mathrm{O}$ ato estético dá à luz o existir em um novo plano axiológico do mundo, nascem um novo homem e um novo contexto axiológico - o plano do pensamento sobre o mundo humanizado.

O autor assume, assim, um grau extremo de objetividade em relação ao universo representado e às criaturas que o povoam, o que o levará a afirmar que o autor-artista não inventa a personagem, ou seja, pré-encontra-a já dada do mundo real, cabendo a ele a tarefa de enformá-la: “O autor-artista pré-encontra a personagem já dada independentemente do seu ato puramente artístico, não pode gerar de si mesmo a personagem - esta não seria convincente" (BAKHTIN, 2011, p.183-4). Importante mencionar, como criatura do mundo real, a autonomia da personagem, uma vez que "o autor cria, mas vê sua criação apenas no objeto que ele enforma, isto é, vê dessa criação apenas o produto em formação e não o processo interno psicologicamente determinado" (BAKHTIN, 2011, p.5). A voz do outro, refratada pelo olhar do autor-criador, estará presente, será reconhecível no texto, isto é, na concepção bakhtiniana, se a autonomia do outro desaparece, desaparece, também, a linguagem romanesca.

A posição axiológica do autor-criador é, nesse sentido, um modo de ver o mundo, um princípio ativo de ver que guia a construção do objeto estético e direciona o olhar do leitor, chamado por Bakhtin (2011) de autor-contemplador, que, igualmente, necessitará de distância, a exotopia, para atualizar o objeto estético, que, no caso deste estudo, são romances e, em especial, contos de Machado de Assis.

Nesse processo de criação, o texto literário apresenta uma face dupla: a leitura-escritura, já que a adaptação da linguagem literária para a cinematográfica amplia diversas formas de conhecimento, utilizando-se da palavra e da imagem como ferramentas de criação dos roteiros, que são o guia para a elaboração do curta-metragem. Além de pensar no enunciado, faz-se necessário pensar na enunciação, considerando os recursos de áudio, as músicas, a voz (ou vozes), ou não, que narra(m), as personagens, sua caracterização e atuação, além do tempo, da iluminação, dos espaços. Muito mais que a escrita de um roteiro, temos aí a convergência de multiletramentos, que possibilitam aos alunos projetarem a melhor forma de fazer seus discursos circularem, pois, além da história a ser contada, precisam pensar em como contá-la. 
Após a escrita, essa produção torna-se fonte de fruição de leitura, uma vez que os roteiros são, inicialmente, disponibilizados aos colegas para leitura e, em momento posterior, apresentados pelos roteiristas. Agora, de ouvintes de histórias, os estudantes passam a contadores das "suas" histórias. Nesse momento, além de o aluno "contar" o seu roteiro para a turma, também divide um pouco da sua experiência com a leitura das narrativas do escritor Machado de Assis, explica por que produziu aquela história, quais semelhanças e diferenças com a obra machadiana, por que determinado texto foi escolhido, enfim, divide a experiência de leitor e de escritor com os colegas.

Concluída a fase de apresentações, passa-se a pensar na gravação dos roteiros. Em grupos, os alunos decidem quem serão os atores, editores, diretores, maquiadores, figurinistas... Todos participam de alguma forma com aquilo que sabem ou que gostariam de fazer/aprender. É um momento de discussão, de "apoderar-se" do texto e, ainda, de sugerir adaptações para que ele realmente possa ser gravado.

Ao transformar o roteiro em um curta-metragem, permite-se a circulação mais efetiva do produto entre os alunos e a comunidade escolar, além de promover a discussão crítica de temas próprios da adolescência, que emergem juntamente com os temas machadianos, como: violência, drogas, relacionamentos, família, morte, vida... A produção audiovisual, ao longo desses anos de Projeto, tem sido fundamental na divulgação e na apropriação dos textos literários, possibilitando, para além da escola, a mobilização de novas formas de produção, circulação e recepção de discursos na contemporaneidade, com vistas à formação cidadã voltada para o desenvolvimento crítico dos alunos.

Ainda, em momento anterior às filmagens, que são realizadas pelos alunos, com equipamentos próprios (filmadoras e/ou celular) ou, então, emprestados da escola, os alunos são convidados a participar de workshops de filmagem, direção, edição, fotografia, cenário, maquiagem, figurino, para que possam compreender um pouco melhor os bastidores das câmeras e se instrumentalizar para produzir seus curtas com qualidade. Nesses momentos, novamente, reflete-se sobre os textos e produzem-se fichas de gravação com anotações importantes que conduzirão os trabalhos. Aqui, mais uma vez, é possível depreender, pela enunciação, aspectos axiológicos, seja na escolha dos atores, dos espaços, dos objetos que dão mais significado ao cenário, do estilo da roupa, da maneira de caminhar, da mania de algum 
personagem, tudo tem algo a dizer.

Após um mês de intenso trabalho, os curtas estão prontos, filmados e editados pelos próprios alunos, com uma média de dez minutos de duração. Cabe considerar que a escola disponibiliza, para uso no espaço escolar, de filmadora e tripé para as gravações e computadores para edição. Contudo, considerando as limitações espaciais e temporais, a maioria dos grupos opta por realizar as filmagens com equipamentos próprios ou, então emprestados. O mesmo ocorre com as edições dos vídeos.

Muito mais que histórias, os curtas, escritos e produzidos pelos próprios alunos, trazem consigo o olhar de uma geração, sobre si e o outro, seus hábitos culturais, seus posicionamentos ideológico-políticos, seus traços identitários, seus sonhos e utopias, que são compartilhados, em uma noite de estreia, com a comunidade escolar, que, por sua vez, mais que assistir aos filmes, tem a oportunidade de conhecer um pouco mais sua juventude.

\section{Projeto Outros Olhares: um olhar sobre o curta "Ela"}

Para fins de análise, considerando as limitações espaciais, elencamos um roteiro e o seu respectivo curta, produzidos durante o ano de 2018, a partir do conto "O Alienista" - publicado em 1882 na obra "Papéis Avulsos" e considerado por muitos críticos, dada a sua extensão, como uma novela - e do poema "Ela" - suposto primeiro poema publicado pelo autor, em 1855, quando este contava apenas 16 anos de idade. O roteiro e o curta-metragem homônimo, intitulado "Ela"7, tem a escrita e a direção de uma aluna da segunda etapa do primeiro ciclo do Ensino Médio, na época também com 16 anos.

A sinopse do curta apresenta a história de Joaquim (primeiro nome de Machado de Assis), que tem apenas 17 anos e vem de uma situação socioeconômica desfavorável. "Para lidar com a frustração e raiva, o maior refúgio e interesse de Joaquim acabou tornando-se a arte". Assim, começa a desenhar tudo o que vê a sua volta, até encontrar-se com o olhar de uma jovem, que lhe prende, como o de Capitu (embora "Dom Casmurro" não seja citado como inspiração). De acordo ainda com a sinopse, "Ela tinha olhos que passavam mais do que os da maioria. Ela tinha uma complexidade extrema". A obsessão pelo olhar acaba arrastando

${ }^{7} \mathrm{O}$ curta-metragem pode ser assistido em: https://www.youtube.com/watch?v=5OF-n53ptHQ.

Periódico Horizontes - USF - Itatiba, SP - Brasil - e020023 
Joaquim inexoravelmente a sua ruína à medida que "Ela" leva-o à incerteza de que sua presença possa ser fruto da sua própria alucinação. Essa incerteza se torna inconteste quando o roteiro apresenta não uma personagem feminina, mas duas "elas". A primeira, com um papel psicótico imaginário, cujo objetivo "é oprimi-lo de forma que consiga tirar o máximo de medo e insegurança dele; enquanto a segunda é caracterizada como "uma jovem estudante de 16 anos que começa a se sentir atormentada por olhares de Joaquim".

Até o minuto 3'15', a narrativa se constrói na simbiose da ação das personagens e da trilha sonora, sem qualquer diálogo ou intervenção de algum narrador. Esse silêncio que acompanha as personagens, que são adolescentes, pode, a nosso ver, ser visto como o núcleo ativo da palavra, que, "no breve instante em que dele (do silêncio) procede, é um grito: o que todas as convenções sociais nos (Ihes) ensinaram a calar" (BARTHES, 1986, p.160). O silêncio se apresenta, nesse sentido, aos interlocutores, como o limite da palavra, da representação do mundo e do seu lugar nesse mundo, um lugar vazio que se oferece aos sentidos possíveis, às infinitas possibilidades do imaginário. É, pois, no silêncio que algo continua a ressoar, algo que, embora não expresso em palavras, subjaz o discurso.

O curta tem em torno de 13 minutos e apresenta uma história que pode ser interpretada de várias maneiras. Essa possibilidade, aliada ao silêncio que acompanha grande parte das cenas, remete-nos diretamente ao mal-estar característico à pós-modernidade. Como caracterizado por Bauman (1998), ao passo que as sociedades ocidentais oferecem, dia após dia, cada vez mais a possibilidade de escolha aos indivíduos, essa imensidão de alternativas nos coloca diante da dissolução de todas as certezas que, até então, consolidavam uma ontologia do sujeito moderno.

Nesse sentido, torna-se interessante percebermos, a partir da análise do discurso, os atravessamentos considerados por Bakhtin (2011), os quais indicam a impossibilidade de se pensar na dinâmica discursiva por meio de uma perspectiva individual. Assim, quando olhamos para as possibilidades que constituem hoje a identidade dos jovens, é plausível que essa dinâmica seja causadora de uma angústia sem precedentes. Bauman (2001), quando caracteriza as dinâmicas sociais contemporâneas como líquidas, refere-se justamente à rapidez dos afetos, à volatidão das certezas, assim como à efêmera e frágil possibilidade de escolha.

O espaço da narrativa descrito no roteiro e a consequente escolha das locações para 
gravação do curta-metragem revelam questões axiológicas. Trata-se de adolescentes urbanos, que "observam", "ouvem", que transgridem, se entorpecem e têm necessidade de deixar suas marcas, são jovens que têm algo a dizer ao mundo: "Eu tinha que deixar aquilo marcado. Mostrar o que eu queria que todos vissem: arte, em forma de arte" (voz dos pensamentos de Joaquim, entre os minutos 5'23" e 5'31", quando picha o olhar "dela", na calada da noite, em um muro). Para além de transgressão, pichar, nos interstícios narrativos, é arte e traz consigo a possibilidade/necessidade de dizer ao mundo aquilo que de outra forma não seria dito. A mochila, os fones, o skate, o caderninho, o lápis, o spray, eis os parceiros diários de Joaquim. As cenas 3, 5 e 8, que seguem, trazem, para fins de exemplificação, mais um pouco desse universo em que os jovens estão imersos:

\section{INT. ESTAÇÃO DE TREM - DIA}

Joaquim se senta, observa a paisagem, mexe um pouco no celular e logo tira um caderninho de sua mochila juntamente com um lápis [...].

5 EXT. RUA - DIA

Joaquim para no lado de fora, leva uma das mãos ao ouvido e retira o fone, ouve o barulho da rua e logo coloca o fone novamente. [...]

8 EXT. RUA - NOITE

Joaquim anda com o skate na mão pela rua.

Anda de skate, observando os lugares.

Para em frente a um muro e larga a mochila escorada.

Ele tira um molde e um spray da mochila [...].

Para a gravação, os alunos optaram por uma praça próxima à escola, cenas em ruas de ambiente urbano e da capital, estação e interior de Trensurb, estacionamento da escola e pista de skate. São espaços comuns utilizados pelos alunos no dia a dia e que nos revelam, na construção narrativa, a forma como percebem esse mundo e, ao mesmo tempo, como se percebem nele. Trata-se de espaços sociais frequentados por muitas pessoas, que, embora estejam juntas, estão sós, distantes, solitárias. Em determinada cena do curta (9'08'), justamente em momento de alucinação do protagonista, um flash de uma "casa verde" faz alusão ao conto "O Alienista" - no mundo real, trata-se de uma casa abandonada situada em rua próxima à escola, a qual, muitas vezes, serve de abrigo para usuários de drogas. É a intertextualidade e as inferências fazendo-se presentes nas produções dos adolescentes e, 
nesses interstícios, fazendo-nos pensar na sociedade, que, muitas vezes, vê, mas finge não ver, ouve, mas não escuta, como subterfúgio.

Ao transformar o roteiro em um curta-metragem, permite-se a circulação mais efetiva do produto entre os alunos e a comunidade escolar, além de promover a discussão crítica de temas próprios da adolescência, que são trazidos juntamente com os temas machadianos, como: violência, drogas, relacionamentos, família, morte, vida... A comunidade escolar, por sua vez, tem a possibilidade de conhecer um pouco mais seus jovens, seus medos, seus anseios, suas transformações e angústias diante do mundo, assim como seu olhar sobre si e o outro, seus hábitos culturais, seus posicionamentos ideológico--políticos, seus traços identitários, seus sonhos e utopias.

\section{Considerações finais}

No Ensino Médio, em uma faixa etária em que o infantil já não serve mais, mas o mundo adulto, por vezes, ainda parece distante, os adolescentes buscam formar e fortalecer suas novas identidades. Nesse sentido, projetos que promovam a participação ativa, crítica e criativa dos jovens, que possibilitem a escuta atenta, a criação de espaços que favoreçam a expressão, a diversidade, a aprendizagem significativa, que promovam o protagonismo juvenil, em que o professor se coloca como mediador do processo, parecem-nos imprescindíveis na contemporaneidade.

Ao longo dos anos, o "Projeto Outros Olhares" tem considerado esses elementos e contribuído para a formação do leitor adolescente, que tem contato com diferentes perspectivas do narrar e a possibilidade de narrar-se, de dizer ao mundo o que, talvez, de outra forma não diria, de exercer autoria, de, ao atualizar a história, por exemplo, significá-la para o tempo presente e, assim, de leitor de mundos passar a criador de mundos. Essa vivência sinaliza um modo oportuno de escolarização da literatura, em que a leitura do texto não é pretexto, mas a essência, é arte, é conhecimento, é fruição. Além disso, considerando aquele que é o mediador desse processo de formação de leitores, o professor, tem aí a possibilidade de, a cada ano, com novos alunos, em novos contextos e novos projetos, reinventar-se e, assim, ressignificar seu fazer, sua ação pedagógica. 
A leitura literária funciona, pois, como direcionamento para a construção de narrativas, as quais permitem aos alunos, adolescentes, pela leitura e, depois, pelas produções, narrarem a si e aos outros e, assim, guiarem-se dentro de sua própria elaboração identitária. Ademais, considerando a complexidade do funcionamento da linguagem contemporânea, em que, a cada dia, a hibridização de esferas, mídias e semioses configuram novas práticas discursivas, os curtas possibilitaram aos alunos leitores, produtores e espectadores, bem como à sociedade em geral, pela mobilidade de circulação dos curtas, por exemplo, não só analisar, discutir e refletir sobre os discursos instaurados em suas teias de relações, mas, pelos interstícios narrativos, contrapô-los aos massivos e hegemônicos.

\section{Referências}

BAKHTIN, M. Marxismo e filosofia da linguagem: problemas fundamentais do método sociológico da linguagem. Trad. Michel Lahud e Yara F. Vieira. 12.ed. São Paulo: Hucitec, 2006.

BAKHTIN, M. Problemas da poética de Dostoiévski. Trad. Paulo Bezerra. 5.ed. Rio de Janeiro: Forense, 2010.

BAKHTIN, M. Estética da criação verbal. Trad. Paulo Bezerra. 6.ed. São Paulo: Editora WMF Martins Fontes, 2011.

BARTHES, R. O rumor da língua. Lisboa: Edições 70, 1986.

BARTHES, R. Aula. São Paulo: Cultrix, 1989.

BAUMAN, Z. O mal-estar da pós-modernidade. Rio de Janeiro: Jorge Zahar, 1998.

BAUMAN, Z. Modernidade líquida. Rio de Janeiro: Jorge Zahar, 2001.

CALVINO, I. Por que ler os clássicos. Trad. Nilson Moulin. São Paulo: Companhia das Letras, 1993.

CANDIDO, A. Vários escritos. 3.ed. São Paulo: Duas Cidades, 1995.

ISER, W. A interação do texto com o leitor. In: JAUSS, H.R. et al. A literatura e o leitor: textos de estética da recepção. Rio de Janeiro: Paz e Terra, 1979, p.83-132.

ISER, W. O fictício e o imaginário: perspectivas de uma antropologia literária. Trad. Johannes Kretschmer. Rio de Janeiro: UERJ, 1996. 
ISER, W. A indeterminação e a resposta do leitor na prosa de ficção. Trad. Maria Angela Aguiar. Cadernos do Centro de Pesquisas Literárias da PUCRS - Série Traduções, Porto Alegre, v.3, n.2, p.1-47, mar. 1999.

LARROSA, J. La experiência de la lectura: estudos sobre literatura y formación. México: Fondo de Cultura Económica, 2003.

SEARLE, J. R. Expressão e significado: estudo das teorias dos atos da fala. Trad. Ana Cecília G. A. Camargo e Ana Luiza M. Garcia. 2.ed. São Paulo: Martins Fontes, 2002.

Recebido em setembro 2019.

Aprovado em março 2020. 